\title{
Modelling and Production of Injection Moulded Polyvinylchloride--Sawdust Composite
}

\author{
${ }^{*}$ ALIYEGBENOMA, CO; ${ }^{1}$ APKOBI, JA; ${ }^{2}$ OLODU, DD \\ ${ }^{I}$ Departmennt of Production Engineering, Faculty of Engineering, University Of Benin, Benin City, Edo State, Nigeria \\ ${ }^{2}$ Departmennt of Mechanical Engineering, Faculty of Engineering, Benson Idahosa University, Benin City, Edo State, Nigeria \\ *Corresponding Author Email: cyril.aliyegbenoma@eng.uniben.edu
}

\begin{abstract}
This study focused on the modeling and production of the injection moulded PolyvinylchlorideSawdust (PVC-sawdust) composite. The PVC material and sawdust were mixed together to form a homogenous mixture with various percentage composition by volume as recommended by the central composite design (CCD). The two screw plunger injection moulding machine with maximum clamping force of 120 tons and shot capacity of $3.0 \mathrm{oz}$ was used to produce Polyvinylchloride-Sawdust (PVC-Sawdust) composite at various temperature. The produced composites were evaluated for their mechanical properties which included tensile strength, proof stress, percentage elongation and flexural strength. The response surface methodology (RSM) was used to determine the effect of the interaction of temperature, material type and percentage by volume of material on the mechanical properties of the produced PVC-sawdust composite. The optimization results for PVC-Sawdust composite shows that the tensile strength, proof stress, flexural strength and flexural modulus were maximized with values of $43.70 \mathrm{MPa}, 48.38 \mathrm{MPa}, 61.41 \mathrm{MPa}$ and $3.42 \mathrm{GPa}$ respectively obtained at barrel temperature of $224.65^{\circ} \mathrm{C}$ and polymer level of $61.46 \%$ respectively while percentage elongation and average deflection were minimized with values of $65.43 \%$ and $4.23 \mathrm{~cm}$ respectively. A desirability of 0.952 was obtained which shows the adequacy of the model terms. The models were validated using coefficient of determination $\left(\mathrm{R}^{2}\right)$. The coefficient of determination $\left(\mathrm{R}^{2}\right)$ obtained ranged from $0.9213(92.13 \%)$ to $0.981(98.10 \%)$ which indicates that a substantial good fit was achieved by the model developed. The values obtained from the validation of these models were therefore found to be satisfactory, and shows good predictability of the model and its adequacy.
\end{abstract}

DOI: https://dx.doi.org/10.4314/jasem.v23i12.12

Copyright: Copyright $(C 2019$ Aliyegbenoma et al. This is an open access article distributed under the Creative Commons Attribution License (CCL), which permits unrestricted use, distribution, and reproduction in any medium, provided the original work is properly cited.

Dates: Received: 14 November 2019; Revised: 18 December 2019; Accepted: 21 December 2019

Keywords: Composite, Modeling, Polyvinylchloride, Sawdust.

The demand for new materials with higher specifications has led to the concept of combining different materials to form a single material called composite. Such composite materials results in high performance, and high flexibility in design that cannot be attained by the individual constituents Mostafa and Mohamed (2017). Moreover, it has been shown that technological development depends on the progress in the field of material sciences. The research and development of new materials together with its de sign is the engine that drives economic progress. That is to say, today, technology depends greatly on scientific research of materials, and this contributes to economic growth of any nation Andrew (2014). Furthermore, injection moulding is a cost-effective way to produce complex, three shapes at high volumes. In the plastic industry, injection moulding makes up approximately $32 \%$ weight of all plastic processing methods, second only to extrusion which is $36 \%$ weight Jozsef and Tibor (2005). A qualitative analysis of the influence of these factors in this case barrel temperature on the mechanical properties of a moulded part will be helpful in gaining better insight into the presently used processing methods. Moreover, there are inadequate models to predict mechanical properties and determine the interaction of some process variables of PVCsawdust composite.

Shubbar (2013) examined the effect of temperature on high density Polyethylene Crates, he evaluated for tensile strength, proof stress, Percentage elongation and flexural strength at a barrel temperature of $140^{\circ} \mathrm{C}$. The result shows that temperature had effects on the mechanical properties of the produced material. In the work of Mosle et al (2009) on sawdust-PET composite using the hot press compression moulding, the tensile strength, proof stress, the percentage elongation, the flexural strength were found to be favourably. Osarenmwinda and Nwachukwu (2010) focused on the development of empirical models making use of previously obtained experimental data to estimate properties of produced composite material from agro waste (sawdust and palm kernel shell). The empirical model was used to predict the properties of composite material (hardness, yield strength, ultimate tensile strength, modulus of elasticity, modulus of rupture, internal bond strength, density, thickness of swelling and water absorption) taking the inputs as percentage 
sawdust composition and percentage palm shell composition respectively. The empirical model was developed using "mathematical product" software program expressing the outputs in the quadratic form. The model performances were found to be satisfactory and show good predictability. Komeil et al (2017) examined the designing, modeling and manufacturing of lightweight carbon nanotubes/polymer composite nanofibers for electromagnetic interference shielding application. The predicted responses were in good agreement with the experimental results according to RSM model. Olodu and Osarenmwinda (2019) focused on the investigation of polypropylene-Grass composite using split-split plot experimental design, the results obtained from their study shows that there is strong interaction between the process parameters such as material type, percentage by volume of material and barrel temperature. This study therefore focuses on modelling and production of injection moulded Polyvinylchloride--Sawdust composite

\section{MATERIALS AND METHODS}

Materials and Equipment: The following are the materials and equipment used for this study:

(i) Polyvinyl chloride (PVC) in powder form which were available at Adig plastics company ltd.

(ii) Sawdust (from Mahogany tree) obtained from saw mill in Benin City, Edo State.

(iii) Two stage-screw plunger Injection machine Fox and offord, 120 tons two stage-screw plunger, A toggle clamp attached to the injection end of injection moulding, An existing mould belonging to Adig Plastic Ltd,

(iv) Monsanto Tensometer, Type 'W' Serial No. 8991, The mould was made of Silicon - killed forging quality steel AISI type H140 treated to 252-302 Brine 11. to use at high clamping pressures.

Design of Experiment: For this study, a two-variable central composite design (CCD) was used to plan the experiments, develop statistical models for predicting the chosen responses. The design points were made up of $2 n$ factorial points as well as star points. The star points are particularly necessary for estimating the response for non-linear models Amenaghawon et al (2014).

Models Development: Design Expert software version 7.0.0, (Stat-ease, Inc. Minneapolis, USA) was used to design the experiment and to analyze the experimental data obtained. The factors considered were temperature and the level of polymer (PVC) in the matrix. The range and levels of these factors are shown in Tables 1 to 3 and they were calculated using Equation.1 Montgomery, (2005). In this case, the responses chosen for consideration were tensile strength, proof stress, percentage elongation, average deflection, flexural strength, and flexural modulus.

$$
x_{i}=\frac{X_{i}-X_{0}}{\Delta X_{i}}
$$

Where $x_{i}$ and $X_{i}$ are the coded and actual values of the factors respectively while $X_{o}$ is the actual value of the factors at the centre point, and $\Delta X_{i}$ is the step change in the value of the actual values of the factors.

In selecting the appropriate model for predicting the responses, different model types in the Design Expert software library were considered and these include linear, two-factor interaction (2FI), quadratic and cubic models. The first type of model usually investigated is a linear model shown in Equation 2. It is usually proposed to predict the response of the dependent variables and to predict their optimum values when the relationship between the factors and the responses is thought to be linear.

$$
Y=b_{0}+\sum_{i=1}^{N} b_{i} X_{i}+\sum_{i=1}^{N} e_{i}
$$

Where $Y_{i}$ is the dependent variable or predicted response, $X_{i}$ is the independent variables, $b_{o}$ is offset term, $b_{i}$ is the regression coefficient and $e_{i}$ is the error term.

Equation (3) is a two-factor interaction regression model which was also proposed to predict the response of the dependent variables and to predict their optimum values.

$$
Y=b_{0}+\sum_{i=1}^{N} b_{i} X_{i}+\sum_{i, j=1}^{N} b_{i j} X_{i} X_{j}+\sum_{j=1}^{N} e_{i}
$$

$X_{j}$ is the independent variables or factors while $b_{i j}$ is the coefficient of the interaction terms.

For situations where the relationship between the factors and the responses is thought to be nonlinear, a second order model as shown in Equation 4 can be used to predict the response.

$$
\begin{aligned}
Y=b_{0}+\sum_{i=1}^{N} b_{1} & X_{1}+\sum_{i, j=1}^{N} b_{i j} X_{i} X_{j}+\sum_{i=1}^{N} b_{i i} X_{i}^{2} \\
& +\sum_{i=1}^{N} e_{i}
\end{aligned}
$$

The second order model is the most widely used model for response surface methodology Carley et al (2004). This is because it is flexible and parameters of the model are easy to estimate using the popular least squares method used by the Design Expert software. Beyond that, experience has shown that this model is most suitable in representing most real-life situations. 
Statistical Analysis of Model Results: The statistical analysis of the results was carried out using the Design Expert software. The fit of the models representing the responses (tensile strength, proof stress, percentage elongation, average deflection, flexural strength, and flexural modulus) was determined using analysis of variance (ANOVA). The ANOVA results helped to also assess the statistical significance of the models representing the responses and this was done using parameters line $\mathrm{p}$ value, $\mathrm{F}$ value, sum of squares, mean square, lack of fit, standard deviation, coefficient of variation, coefficient of determination $\left(\mathrm{R}^{2}\right)$, adjusted $\mathrm{R}^{2}$, adequate precision, predicted residual sum of squares (PRESS). These parameters are discussed in the following sections.

The Moulding Process: The PVC material and sawdust were mixed together to form a homogenous mixture with various percentage composition by volume as recommended by the central composite design (CCD). The two screw plunger injection moulding machine with maximum clamping force of 120 tons and shot capacity of $3.0 \mathrm{oz}$ was used to produce Polyvinylchloride-Sawdust (PVC-Sawdust) composite at various temperature. The produced composites were evaluated for their mechanical properties which included tensile strength, proof stress, percentage elongation and flexural strength.
Equations 5 to 8 were used to evaluate for mechanical strength.

$$
T S=\frac{\text { maximum load }}{\text { original cross sectional area }}
$$

The original cross-sectional area of the specimen is $18.9 \mathrm{~mm}^{2}$.

$$
\text { proof stress }=\frac{\text { force at yield }}{\text { cross sectional Area }}
$$

The Cross-sectional area of specimen $=18.9 \mathrm{~mm}^{2}$

$$
\begin{gathered}
\text { Hence, proof stress }=\frac{\text { Force at yield }}{18.9} \mathrm{~N} / \mathrm{mm}^{2} \\
(\%) \text { elongation }=\frac{\text { extension }}{\text { gauge length }} \times 100 \\
\text { flexural strength }(E I)=\frac{P L^{3}}{48 y}
\end{gathered}
$$

Where TS is tensile strength, $\mathrm{y}$ is the deflection in $\mathrm{mm}$, $\mathrm{P}=$ Load, $\mathrm{L}=$ Length of test specimen

\section{RESULTS AND DISCUSSION}

The range and levels of these factors are shown in Table 1 and they were calculated using Equation.1 (Montgomery, 2005). In this case, the responses

\begin{tabular}{|c|c|c|c|c|c|c|c|}
\hline \multirow{2}{*}{ Factors } & \multirow{2}{*}{ Unit } & \multirow{2}{*}{ Symbols } & \multicolumn{5}{|c|}{ Coded and Actual Levels } \\
\hline & & & -1.414 & -1 & 0 & 1 & 1.414 \\
\hline Temperature & ${ }^{\circ} \mathrm{C}$ & $\mathrm{X}_{1}$ & 210.00 & 224.64 & 260.00 & 295.36 & 310.00 \\
\hline PVC level & $\%$ & $\mathrm{X}_{2}$ & 60.00 & 61.46 & 65.00 & 68.54 & 70.00 \\
\hline
\end{tabular}
chosen for consideration were tensile strength, proof stress, percentage elongation, average deflection, flexural strength, and flexural modulus.

Table 1: Coded and actual levels of the factors for PVC polymer composite

Determination of Appropriate Model: This decision was reached based on the statistical parameters backing up the quadratic model. Among a number of alternatives, the model chosen should be the one with the desirable statistical parameters such as high $\mathrm{R}^{2}$ value, low standard deviation, and low PRESS. The quadratic model was found to have the highest $\mathrm{R}^{2}$ values for all the responses for the PVC-Sawdust composite. The quadratic model was also found to have the lowest standard deviation and PRESS for the PVC-Sawdust composites. The linear model was discarded because it performed poorly in predicting the responses (low $\mathrm{R}^{2}$ values and high standard deviation). Even though the cubic model displayed some desirable statistical properties, it was however not chosen because it was flagged as "aliased". These observations were also corroborated by the results obtained from the lack of fit test carried out for PVCSawdust composite. The quadratic model was shown to have insignificant lack of fit, a situation that is desirable. Thus, the quadratic model was adopted for predicting the responses under investigation in this study i.e. tensile strength, proof stress, percentage elongation, average deflection, flexural strength, and flexural modulus.

Statistical Analysis of Models: Statistical analysis of the quadratic model was carried out. This was done by fitting the quadratic model to the experimental data obtained for all the responses. There were a total of 13 experimental runs as shown in Table 2 and 3 for (PVCSawdust composite). After fitting the quadratic model to the experimental data, the model parameters were estimated to obtain the final model equations in terms of actual experimental factors. The model equations for the respective responses and the different composite materials are summarised as follows. The equations represent tensile strength, proof stress, percentage elongation, average deflection, flexural strength, and flexural modulus as a function of temperature $\left(\mathrm{X}_{1}\right)$ and level of polymer $\left(\mathrm{X}_{2}\right)$. 
Table 2: Experimental and RSM predicted results for tensile strength (PVC composite)

\begin{tabular}{lllllll}
\hline Run & \multicolumn{2}{l}{ lactors } & \multicolumn{4}{l}{ Response } \\
\cline { 2 - 6 } & \multicolumn{2}{l}{ Coded values } & \multicolumn{2}{l}{ Actual values } & \multicolumn{2}{l}{ Tensile strength (MPa) } \\
\cline { 2 - 6 } & X1 & X2 & X1 & X2 & Experiment & Predicted \\
\hline 1 & -1 & 1 & 224.64 & 68.54 & 37.90 & 35.64 \\
2 & 1 & -1 & 295.36 & 61.46 & 43.50 & 44.38 \\
3 & -1.414 & 0 & 210.00 & 65.00 & 37.70 & 39.09 \\
4 & 1.414 & 0 & 310.00 & 65.00 & 37.20 & 37.18 \\
5 & 1 & 1 & 295.36 & 68.54 & 33.50 & 32.24 \\
6 & 0 & -1.414 & 260.00 & 60.00 & 47.80 & 46.97 \\
7 & 0 & 1.414 & 260.00 & 70.00 & 30.50 & 32.70 \\
8 & 0 & 0 & 260.00 & 65.00 & 36.85 & 37.15 \\
9 & -1 & -1 & 224.64 & 61.46 & 43.80 & 43.68 \\
10 & 0 & 0 & 260.00 & 65.00 & 36.90 & 37.15 \\
11 & 0 & 0 & 260.00 & 65.00 & 36.80 & 37.15 \\
12 & 0 & 0 & 260.00 & 65.00 & 37.50 & 37.15 \\
13 & 0 & 0 & 260.00 & 65.00 & 37.70 & 37.15 \\
\hline
\end{tabular}

PVC composite:

$$
\begin{aligned}
& \text { Tensile stress }=477.19+0.31 X_{1}-13.27 X_{2}-0.0082 X_{1} X_{2}+0.00040 X_{1}^{2}+0.11 X_{2}^{2} \\
& \text { Proof stress }=491.59+0.38 X_{1}-13.88 X_{2}-0.0084 X_{1} X_{2}+0.00029 X_{1}^{2}+0.11 X_{2}^{2} \\
& \text { Percentage elongation }=2761.96-0.059 X_{1}-85.16 X_{2}-0.0020 X_{1} X_{2}+0.00038 X_{1}^{2}+0.68 X_{2}^{2} \\
& \text { Average deflection }=-98.87+0.034 X_{1}+2.84 X_{2}-0.00060 X_{1} X_{2}+0.000011 X_{1}^{2}-0.019 X_{2}^{2} \\
& \text { Flexural strength }=636.26-0.34 X_{1}-15.30 X_{2}+0.0064 X_{1} X_{2}-0.00012 X_{1}^{2}+0.096 X_{2}^{2} \\
& \text { Flexural modulus }=77.02+0.034 X_{1}-2.24 X_{2}-0.00068 X_{1} X_{2}+0.000013 X_{1}^{2}+0.017 X_{2}^{2}
\end{aligned}
$$

Equations 9 to 14 were used to predict the tensile strength, proof stress, percentage elongation, average deflection, flexural strength, and flexural modulus for the PVC-Sawdust composite and the results are shown in tables 2 and 3 for tensile strength and proof stress respectively.

Table 3: ANOVA results for model representing tensile strength (PVC-Sawdust composite)

\begin{tabular}{lccccc}
\hline Sources & $\begin{array}{c}\text { Sum of } \\
\text { Squares }\end{array}$ & $\begin{array}{c}\text { Degree of } \\
\text { freedom }\end{array}$ & $\begin{array}{c}\text { Mean } \\
\text { Squares }\end{array}$ & F value & p value \\
\hline Model & 224.81 & 5 & 44.96 & 20.12 & 0.0005 \\
$\mathrm{X}_{1}$ & 3.65 & 1 & 3.65 & 1.64 & 0.2418 \\
$\mathrm{X}_{2}$ & 203.68 & 1 & 203.68 & 91.12 & $<0.0001$ \\
$\mathrm{X}_{1} \mathrm{X}_{2}$ & 4.20 & 1 & 4.20 & 1.88 & 0.2127 \\
$\mathrm{X}_{1}{ }^{2}$ & 1.70 & 1 & 1.70 & 0.76 & 0.4126 \\
$\mathrm{X}_{2}^{2}$ & 12.56 & 1 & 12.56 & 5.62 & 0.0496 \\
Residual & 15.65 & 7 & 2.24 & & \\
Lack of Fit & 14.95 & 3 & 4.98 & 28.47 & 0.0837 \\
Pure Error & 0.70 & 4 & 0.18 & & \\
Cor Total & 240.46 & 12 & & & \\
\hline
\end{tabular}

The other statistical parameters that were used to assess the significance and fit of the response models are presented in Table 3. All the models were characterised by high $R^{2}$ value and adjusted $R^{2}$ value. The $\mathrm{R}^{2}$ value is used as an indication of model fit. The ideal $R^{2}$ value is unity in which case there is perfect fit between the experimental data and the model prediction. For the results reported in Table 3, the closeness of the $\mathrm{R}^{2}$ value to unity indicates that the models were able to adequately represent the actual relationship between the variables considered in this study. Furthermore, the adjusted $\mathrm{R}^{2}$ values obtained were within reasonable agreement with the corresponding $\mathrm{R}^{2}$ values further confirming the fit of the models. The models displayed very minimal standard deviation compared to the mean. This means that there was very little dispersion about the mean for the data predicted by the models Khuri and Mukhopadhyay (2010). This further corroborates the significant fit of the models. The coefficient of variation (C.V) obtained for the models were relatively small in magnitude. The coefficient of variation indicates the degree of precision with which the runs were carried out. A low value of C.V suggests 
a high reliability and reproducibility of the results Montgomery, (2005). The adequate precision values obtained were all greater than the recommended minimum value of 4 (Myers and Montgomery, 1995). Cao et al. (2009) reported that the adequate precision measures the signal to noise ratio and a value greater than 4 is generally desirable and this means that the models can be used to navigate the design space.

Model Diagnostics: Model diagnostics was carried out to further assess the adequacy of the quadratic models developed to represent the responses and the results are presented in Figure 1. Figure 1 show the normal probability plots representing all the responses for the PVC-Sawdust composites.. This is an important plot which is used to determine whether the residuals follow a normal distribution. A desirable situation is when a normal distribution of the residuals is obtained and this is usually when all the points cluster around the straight line. Indeed, this was the case for the results presented in Figure 1, thus showing that the residuals followed a normal distribution. The models were validated using coefficient of determination $\left(\mathrm{R}^{2}\right)$.
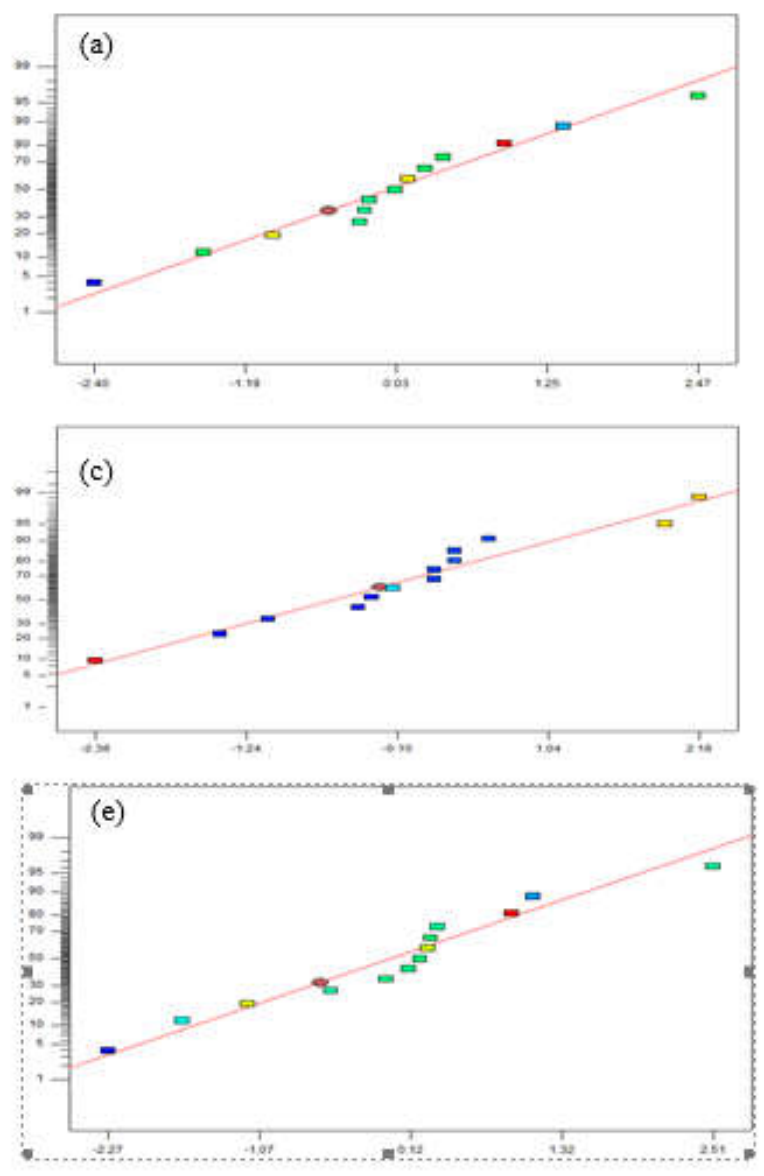

The coefficient of determination $\left(\mathrm{R}^{2}\right)$ obtained ranged from $0.9213(92.13 \%)$ to $0.981(98.10 \%)$ which indicates that a substantial good fit was achieved by the model developed. The optimization results for PVC-Sawdust composite shows that the tensile strength, proof stress, flexural strength and flexural modulus were maximized with values of $43.70 \mathrm{MPa}$, 48.38 $\mathrm{MPa}, 61.41 \mathrm{MPa}$ and $3.42 \mathrm{GPa}$ respectively obtained at barrel temperature of $224.65{ }^{\circ} \mathrm{C}$ and polymer level of $61.46 \%$ respectively while percentage elongation and average deflection were minimized with values of $65.43 \%$ and $4.23 \mathrm{~cm}$ respectively. A desirability of 0.952 was obtained which shows the adequacy of the model terms. The models were validated using coefficient of determination $\left(\mathrm{R}^{2}\right)$. The coefficient of determination $\left(\mathrm{R}^{2}\right)$ obtained ranged from $0.9213(92.13 \%)$ to 0.981 (98.10\%) which indicates that a substantial good fit was achieved by the model developed. The values obtained from the validation of these models were therefore found to be satisfactory, and shows good predictability of the model and its adequacy.
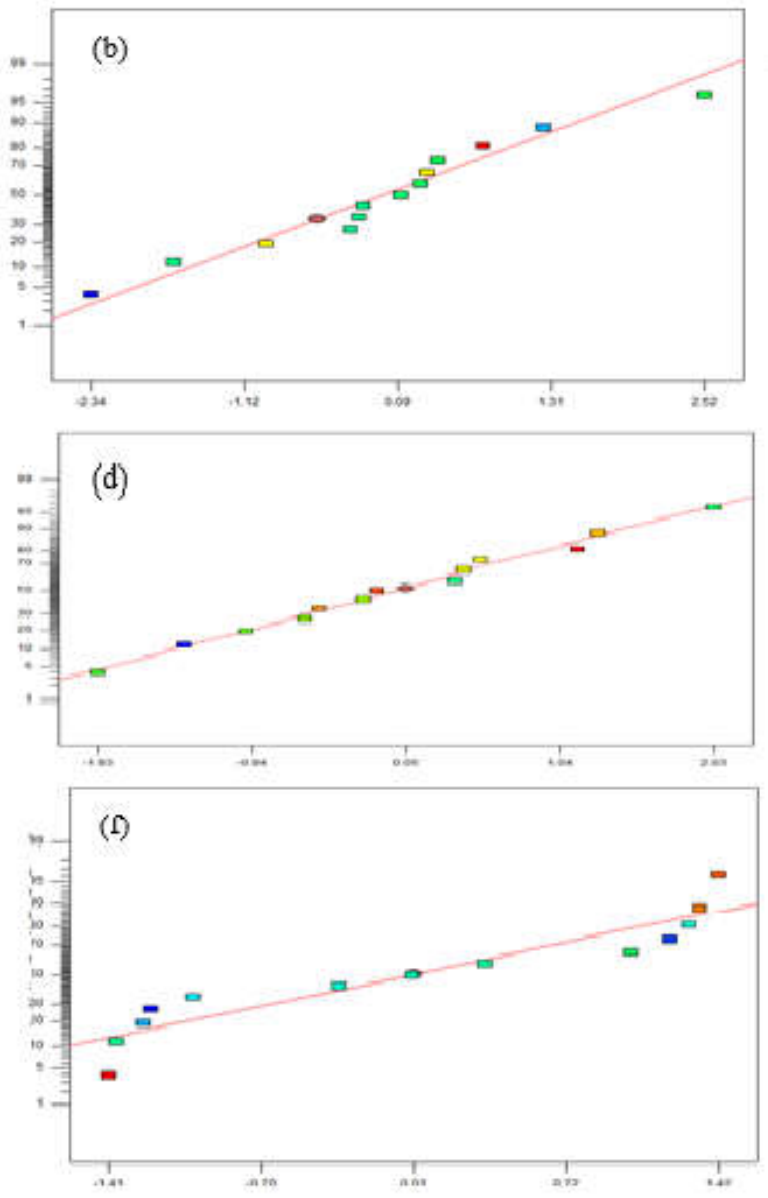

Fig1: Normal probability plot for (a) tensile strength (b) proof stress (c) percentage elongation (d) average deflection (e) flexural strength (f) flexural modulus for PVC composite 
Conclusion: Models were developed for predicting the mechanical properties (tensile strength, proof stress, percentage elongation and flexural strength) for the polyvinylchloride sawdust composite. Sawdust which is considered as a waste has been successful converted to useful product. The interaction of the moulding parameters (temperature, percentage by volume of materials) which poses great challenge on polymeric industries and its effects on the mechanical properties were determined for the polyvinylchloride-Sawdust composite.

\section{REFERENCES}

Amenaghawon, NA.; Ogbeide, SE; Okieimen, CO (2014). Application of statistical experimental design for the optimisation of dilute sulphuric acid hydrolysis of cassava Bagasse. Acta Polytechnica Hungarica, 11(9), 1-12

Andrew, R (2014). The impacts of technological invention on economic growth - a review of the literature, the second machine age: work, progress, and prosperity in a time of brilliant technologies, New York: W.W. Norton \& Co 72-7

Carley, KM; Kamneva, NY; Reminga, J (2004). Response surface methodology. CASOS-center for computational analysis of social and organizational systems technical report, carnegie Mellon University, School of Computer Science, p. 7.

Cao, G; Ren, N; Wang, A; Lee, DJ; Guo, W; Liu, B; Feng, Y; Zhao, Q (2009). Acid hydrolysis of corn stover for biohydrogen production using Thermoanaerobacterium thermosaccharolyticum W16. International Journal of Hydrogen Energy, 34, 7182-7188.

József, GK; Tibor, B (2005). Influence of mold properties on the quality of injection molded parts, Periodica Polytechnica Ser. Mech. Eng. 49(2). 115-122
Khuri, AI; Mukhopadhyay, S (2010). Response surface methodology: Advanced Review. WIRES Computational Statistics, 2, 128-149.

Komeil, A; Mousavi, S (2017). Designing, modeling and manufacturing of Lightweight carbon nanotubes/polymer composite nanofibers for electromagnetic interference shielding application, Journal of Composites Science and Technology. 145, 46-54.

Montgomery, DC (2005). Design and analysis of experiments, 6th ed., New York: John Wiley \& Sons, Inc

Mosle, HG; Bruller, OS; Dick, H (2009). On the influence of the geometry and processing parameters on the mechanical properties of injection moulded plastic, 38th Annual Technical Conference New York Hilton, Published by SPE.

Mostafa, Y; Mohamed, AE. (2017). Additive manufacturing of composite materials: an overview, 6th International Conference on Virtual Machining Process Technology (VMPT), Montréal, May 29th - June 2nd, 2017

Myers, RH; Montgomery, DC (1995). Response Surface Methodology. New York: John Wiley \& Sons.

Olodu, DD; Osarenmwinda, JO (2019). Investigation of Polypropylene-Grass Composite using SplitSplit Plot Experimental Design. Advances in Engineering Design Technology, 1(1); 40-48.

Osarenmwinda, JO; Nwachukwu JC (2010). Development of Composite Material from Agricultural Waste, International Journal of Engineering Research in Africa. 3(1), 42-48.

Shubbar, SDA (2013) Injection Temperature Effects on the Properties of High Density Polyethylene Crates, Journal of Engineering, 19 (6), 752-763. 